\title{
Procurando o lazer na constituinte: sua inclusão como direito social na Constituição de 1988
}

\author{
Flávia da Cruz Santos*
}

\begin{abstract}
Resumo: Este trabalho reconstitui sinteticamente a trajetória do lazer na Assembleia Nacional Constituinte 1987-1988, identificando os atores políticos responsáveis por sua inclusão como direito social na Constituição, bem como os interesses e os significados de lazer envolvidos nesse processo. Privilegia como fontes os documentos produzidos pela Assembleia Nacional Constituinte de 1987-1988. Os vestígios encontrados nos permitem perceber que apesar de o lazer ter sido compreendido como fundamental para a vida dos cidadãos brasileiros por todos os atores políticos participantes desse processo, não houve mobilização e organização em torno do lazer que justificasse sua definição como direito social na Constituição.
\end{abstract}

Palavras-chave: História. Lazer. Direito social.

A Constituição brasileira de 1988, em seu artigo sexto, define os direitos sociais de todos os cidadãos brasileiros, entre os quais se encontra o lazer (BRASIL, 2008). Assim, o lazer é um direito social no Brasil, possui o mesmo status de importância que a educação, a saúde, o trabalho, a moradia, a segurança e a previdência social, por exemplo. Historicamente os direitos sociais estão associados à participação na riqueza social de um país, são entendidos como direitos mínimos e universais, referindose a bens e serviços essenciais aos cidadãos. Como nos diz José Murilo de Carvalho (2007, p. 10), os direitos sociais permitem às sociedades reduzir os excessos de desigualdades produzidos pelo capitalismo e garantir um mínimo de bem-estar a todos, estão baseados na ideia da justiça social. Os direitos sociais são tidos como conquistas dos trabalhadores, como resultado da luta política entre capital e trabalho, que ocorre em cada país de forma diferente, são compreendidos como construções decorrentes de múltiplos

\footnotetext{
Programa de Pós-Graduação Interdisciplinar em Estudos do Lazer, Universidade Federal de Minas Gerais, Belo Horizonte, MG, Brasil. E-mail: flacruz.santos@gmail.com
} 
conflitos e interesses ${ }^{1}$. Portanto, o lazer foi considerado pelo Estado brasileiro, no momento histórico e contexto político da construção da Constituição de 1988, um bem essencial aos cidadãos e ao seu bem-estar, e o acesso a ele foi considerado um fator condicionante da cidadania (MARSHALL, 1967).

Como pode isso acontecer se o lazer naquele momento histórico ainda era tido - mais do que nos dias de hoje - como algo supérfluo, secundário, pouco importante na vida das pessoas, se não houve reivindicação de movimentos sociais por lazer? (MELO; ALVES JUNIOR, 2003, MARCELLINO, 2006, REQUIXA, 1977, MAGNANI, 1996, BRUNHS, 2002, STIGGER, 1988). Foi na trilha dessas reflexões que desenvolvi a pesquisa que originou este texto $^{2}$. Reconstituí a trajetória do lazer na Assembleia Nacional Constituinte de 1987-1988 (ANC), identificando os atores políticos responsáveis por sua inclusão como direito social na Constituição, bem como os interesses e os significados de lazer envolvidos nesse processo.

\section{Metodologia e corpus documental}

Este trabalho origina-se de pesquisa histórica que privilegiou como fontes os documentos produzidos pela Assembleia Nacional Constituinte de 1987-1988 e os que foram produzidos em torno dela, que estão sob a guarda do Fundo Arquivístico da Assembleia Nacional Constituinte e do Senado Federal, cuja localização está indicada em notas de rodapé ao longo do texto. O critério que determinou a escolha das fontes foi a realização de uma relação entre o tema abordado pelas comissões e subcomissões temáticas da ANC e o lazer. Isso se fez necessário pois o lazer não figurou entre os temas que deram nome às subcomissões e comissões temáticas, e que indicavam os assuntos de que elas tratariam.

\footnotetext{
${ }^{1}$ Apoio-me nos trabalhos de LINHALES, (1988); MENICUCCI (2006); VERONEZ (2005); VIEIRA (1999). No entanto, não ignoro a existência de outras abordagens e entendimentos em torno da natureza e significado dos direitos sociais. Ver a respeito em ARRETCHE (1995); COIMBRA (1987); FARIA (1998).
}

${ }^{2}$ Pesquisa financiada pelo CNPq.

Movimento, Porto Alegre, v. 20, n. 4, p. 1305-1327, out./dez. de 2014. 
Esses documentos são fontes do poder, pois produzidos pelos grupos dominantes daquele momento histórico para perpetuar a versão da história que lhes interessava. Mas, ainda assim, foi possível perceber os jogos de poder e de interesse envolvidos na construção da Constituição de 1988. As incoerências entre o que foi dito e o que foi efetivamente realizado, no que se refere à incorporação das sugestões enviadas pela população, pelas entidades e pelos próprios constituintes no texto constitucional são indícios desses jogos. Além de incoerências entre o anunciado, quanto ao lugar ocupado pela população e suas demandas nesse processo, e o de fato acontecido. Esses documentos revelam o que provavelmente desejam ocultar.

Uma fonte oral também compõe o corpus documental da pesquisa. Identifiquei o constituinte que mais enviou emendas aos trabalhos da ANC tendo como tema o lazer, com a intenção de entrevistá-lo para conhecer e compreender os motivos e interesses que o levaram a indicar a inclusão do lazer na Constituição, bem como seu entendimento do tema. O deputado federal Florestan Fernandes, do Partido dos Trabalhadores (PT) de São Paulo enviou o maior número de emendas e sugestões tratando do lazer durante a ANC. No entanto, como ele já é falecido, entrevistei o segundo constituinte que mais enviou emendas tratando do lazer. O exdeputado constituinte do Partido Democrático Trabalhista (PDT) do Rio de Janeiro, José Maurício Linhares Barreto enviou, no total, seis emendas tratando do lazer, que quando não era o único tema da emenda, era um deles. A entrevista foi realizada a partir de um roteiro previamente elaborado, e o deputado autorizou sua utilização em publicações com fins científicos, através da assinatura de um termo de consentimento livre e esclarecido.

O marco temporal desse estudo está determinado pela duração dos trabalhos da Constituinte, assim, o marco inicial é $1^{\circ}$ de fevereiro de 1987 e o marco final é 05 de outubro de 1988, quando da promulgação da Constituição e consequente dissolução da Constituinte. Foram estudados também alguns documentos que datam de antes da instalação da Constituinte, pois eles dizem respeito aos trâmites de sua convocação.

Movimento, Porto Alegre, v. 20, n. 4, p. 1305-1327, out./dez. de 2014. 
Parti desses documentos, eles são a substância desse trabalho. Foram eles que me indicaram os caminhos a percorrer, os estudos e leituras a realizar. Assim, não estudei a priori movimentos sociais ou qualquer ator político por inferir que eles estariam presentes no processo e que seriam responsáveis pela inclusão do lazer como direito social na Constituição. Foi a partir das fontes que identifiquei os atores que deveriam ou não ser estudados por mim, apesar de ter realizado estudos sobre o momento histórico de construção da Constituição de 1988 antes de ter contato com as fontes. Deixei que elas me indicassem o caminho das respostas para as minhas perguntas.

A análise dos documentos foi realizada da seguinte forma: nos relatórios e anteprojetos dos relatores das subcomissões temáticas procurei perceber o trato conferido às sugestões enviadas pelos diferentes atores políticos, além das presenças e ausências do lazer. Confrontei as análises das sugestões enviadas, realizadas pelos próprios relatores e seus assessores, com os anteprojetos dos relatores para conhecer se as sugestões foram consideradas, se foram incorporadas aos anteprojetos. E encontrei diferenças entre o que foi demandado nas sugestões e o texto dos relatores. Analisei as emendas enviadas pelos constituintes a esses anteprojetos para descobrir se o lazer foi ou não reivindicado. Confrontei tais emendas com os anteprojetos das subcomissões para conhecer se elas foram incorporadas ao texto ou não. E, por último, confrontei esses documentos, produzidos por cada subcomissão, com os documentos produzidos pelas comissões, que são, ou deveriam ser, a síntese dos trabalhos realizados pelas três subcomissões que compõem cada uma delas, e que deveriam assim, "refletir as coordenadas gerais da sociedade e da nação brasileira" (BRASIL, 1988a, p. 2) nos temas afetos a cada comissão. Nas comissões analisei ainda as emendas enviadas, e as confrontei com os substitutivos dos relatores e com os anteprojetos das comissões para descobrir se elas foram a eles incorporadas ou não.

Nos documentos produzidos pela "Comissão de Sistematização" e pelo "Plenário" a análise se deu do mesmo modo, 
analisando os documentos produzidos em cada fase dos trabalhos e os confrontando com os documentos das fases posteriores, no intuito de reconstituir a trajetória do lazer nesses trabalhos.

Dada a natureza do conceito de lazer, que é de difícil demarcação e em torno do qual há diferentes compreensões, optei por não partir de um conceito de lazer previamente determinado, de não ter como referência um dado conceito para identificar o que seria ou não analisado. A intenção foi justamente captar o que era tido como lazer pelos envolvidos no processo constituinte, os significados a ele atribuídos naquele momento no Brasil. O meu entendimento de lazer pouco importa, o que importa são os entendimentos de lazer dos atores da Constituinte.

\section{A Assembleia Nacional Constituinte: convocação, DINÂMICA DE FUNCIONAMENTO E INTERESSES ENVOLVIDOS}

Desde, pelo menos, o início da década de 1970 estavam presentes no Brasil pressões pela construção de uma nova Constituição, pois a Constituição de 1967, vigente naquele momento, havia sido construída no e pelo governo do marechal Castello Branco e representava os valores e ideais da ditadura civil-militar. Cartas, manifestos, cartilhas, conferências foram produzidas, além de um abaixo-assinado com mais de 19 mil assinaturas pela convocação da Constituinte. Diferentes organizações da sociedade brasileira, intelectuais, artistas e movimentos sociais reivindicaram a convocação de uma Assembleia Nacional Constituinte para a construção de uma nova Constituição, que seria o marco legal do fim do sistema ditatorial militar (SALGADO, 2005, VERSIANI, 2008).

A partir da segunda metade da década de 1970, teve início a chamada "abertura política". O Ato Institucional número 5 foi revogado, a censura prévia foi extinta, houve diminuição das restrições às propagandas eleitorais e o habeas corpus para crimes políticos foi restabelecido.A taxa de crescimento econômico começou a decrescer e os efeitos do "milagre econômico" desapareceram.

Movimento, Porto Alegre, v. 20, n. 4, p. 1305-1327, out./dez. de 2014. 
Esses fatores se coadunaram e colaboraram para a expansão dos movimentos sociais a partir de 1975. Teve início o movimento sindical de trabalhadores dos novos setores da economia que tinham se expandido durante o "milagre econômico" - metalúrgicos de empresas automobilísticas, de empresas de siderurgia, de máquinas e equipamentos -, a presença e atuação dos sindicatos rurais se tornaram mais fortes, surgiram dentro da Igreja Católica as Comunidades Eclesiais de Base (CEBs), que realizavam um trabalho religioso ligado às condições sociais do povo, e possuía um esforço de conscientização política. Houve a expansão dos movimentos dos favelados, das associações de moradores de classe média e das associações de profissionais de classe média (CARVALHO, 2007). A Ordem dos Advogados do Brasil, a Associação Brasileira de Imprensa e a Sociedade Brasileira para o Progresso da Ciência também adquiriram papel político importante nas décadas de 1970 e 1980.

O auge da mobilização popular foi a campanha pelas "Diretas já!", em 1984, que objetivava forçar o congresso a aprovar emenda constitucional que permitisse eleição direta para presidente da república. Tal objetivo não foi alcançado $^{3}$, mas o Partido do Movimento Democrático Brasileiro (PMDB) lançou um candidato civil para concorrer com o candidato do governo à presidência, e a pressão popular fez de Tancredo Neves o vencedor da disputa, encerrando assim o ciclo de presidentes militares no Brasil ${ }^{4}$. No entanto, seu vice era alguém que ofereceria menos, senão nenhuma, resistência aos planos de "transição lenta gradual e segura" dos militares e das elites econômicas do Brasil, pois era um "antigo servidor dos militares" (CARVALHO, 2007, p. 177). E foi ele, José Sarney, que se fez presidente, "um presidente por circunstância" (FERNANDES, 2006, p. 36).

\footnotetext{
${ }^{3}$ Para ser aprovada a emenda precisava do apoio, em forma de votos, de 2/3 dos membros do Congresso Nacional. Faltaram apenas 22 votos para a emenda ser aprovada.

${ }^{4}$ Essa chegada do PMDB à presidência, depois de anos de oposição, foi fruto de acordos entre diferentes partidos, dentre eles o PDS (ex-Arena), partido governista, que levaram à formação da Aliança Democrática. Assim, "não foi esta uma vitória categórica da esquerda, na medida em que o triunfo, além de formar uma aliança com a "Frente Liberal", contou com largo apoio de parlamentares do PDS." (FREITAS; MOURA; MEDEIROS, 2009, p. 7).
}

${ }^{5}$ Expressão utilizada pelo presidente militar Ernesto Geisel.

Movimento, Porto Alegre, v. 20, n. 4, p. 1305-1327, out./dez. de 2014. 
Era sabido pelos que governavam, pela elite política e econômica do país, que as classes populares acumulavam descontentamentos, frustrações", e que havia "predisposição de vastas populações rústicas para o levante armado" (FERNANDES, 2006, p. 97), que havia predisposição para romper com a ordem vigente e instaurar outra, democrática de fato e não apenas retórica. Assim, a liberalização do sistema, a promoção de um lento retorno à democracia iniciada pelo presidente general Ernesto Geisel, foi uma estratégia de manutenção de uma determinada ordem, pois se assim não fosse feito, o povo, que vinha sendo sufocado há muito na história brasileira, poderia promover um retorno à democracia por vias que não garantiriam o controle do poder pelas classes dominantes (FERNANDES, 2006, GASPARI, 2003). A abertura política foi uma estratégia dos que governavam, uma tentativa de manter o controle burguês sobre o Estado, de evitar rupturas abruptas. O que se engendrava era uma "transição lenta, gradual e segura" para e pelos que controlavam o Estado brasileiro.

Foi nesse bojo, como parte da estratégia de controle do Estado pelas classes burguesas que a ANC foi convocada pelo então Presidente da República José Sarney em 28 de novembro de 1985 (BRASIL, 1985), e em $1^{\circ}$ de fevereiro de 1987 ela foi instalada, no dia seguinte o deputado federal Ulysses Guimarães (PMDB/SP) foi eleito seu presidente e as discussões e trabalhos em torno da construção de uma nova constituição tiveram início. Os trabalhos da ANC foram organizados em oito Comissões Temáticas, e cada uma delas se dividiu em três subcomissões:

Art. 15 As comissões e subcomissões são as seguintes:

\footnotetext{
${ }^{6}$ Nos primeiros anos da década de 1970 a violência do governo do general Garrastazu Médici foi combinada a altos índices de crescimento econômico, foi o denominado "milagre econômico". No entanto, esse crescimento beneficiou de maneira desigual a população, pois as desigualdades ao invés de diminuírem com o crescimento econômico, aumentaram. O salário mínimo valia em 1974 quase a metade do que valia em 1960. Tal general implantou a pena de morte, que havia sido abolida depois da proclamação da República, introduziu a censura prévia em jornais, livros, programas de televisão e de rádio. Não havia liberdade de opinião nem de reuniões, as greves eram proibidas e os sindicatos e órgãos estudantis foram alvo de repressão, estavam sob constante ameaça de intervenção. Havia uma forte demarcação entre o permitido, o lícito, e o não-permitido. O que não servia funcionalmente ao ideário e objetivo do governo militar era coibido e combatido.
}

Movimento, Porto Alegre, v. 20, n. 4, p. 1305-1327, out./dez. de 2014. 
I - Comissão da Soberania e dos Direitos e Garantias do Homem e da Mulher:

a) Subcomissão da nacionalidade, da soberania e das relações internacionais;

b) Subcomissão dos direitos políticos, dos direitos coletivos e garantias;

c) Subcomissão dos direitos e garantias individuais;

II - Comissão da Organização do Estado:

a) Subcomissão da União, Distrito Federal e Territórios;

b) Subcomissão dos Estados;

c) Subcomissão dos Municípios e Regiões;

III - Comissão da Organização dos Poderes e Sistema de Governo:

a) Subcomissão do Poder Legislativo;

b) Subcomissão do Poder Executivo;

c) Subcomissão do Poder Judiciário e do Ministério Público;

IV - Comissão da Organização Eleitoral, Partidária e Garantia das Instituições:

a) Subcomissão do Sistema Eleitoral e Partidos Políticos;

b) Subcomissão de Defesa do Estado, da Sociedade e de sua Segurança;

c) Subcomissão de Garantia da Constituição, Reformas e Emendas; V - Comissão do Sistema Tributário, Orçamento e Finanças:

a) Subcomissão de Tributos, Participação e Distribuição das Receitas;

b) Subcomissão de Orçamento e Fiscalização Financeira;

c) Subcomissão do Sistema Financeiro; VI - Comissão da Ordem Econômica:

a) Subcomissão de Princípios Gerais, Intervenção do Estado, Regime da Propriedade do Subsolo e da Atividade Econômica;

b) Subcomissão da Questão Urbana e Transporte:

c) Subcomissão da Política Agrícola e Fundiária e da Reforma Agrária; VII - Comissão da Ordem Social:

a) Subcomissão dos Direitos dos Trabalhadores e Servidores Públicos;

b) Subcomissão de Saúde, Seguridade e do Meio

Movimento, Porto Alegre, v. 20, n. 4, p. 1305-1327, out./dez. de 2014. 
Ambiente;

c) Subcomissão dos Negros, Populações Indígenas, Pessoas Deficientes e Minorias;

VIII - Comissão da Família, da Educação, Cultura e Esportes, da Ciência e Tecnologia e da Comunicação:

a) Subcomissão da Educação, Cultura e Esportes;

b) Subcomissão da Ciência e Tecnologia e da Comunicação;

c) Subcomissão da Família, do menor e do idoso. (BRASIL, 1987, p.5)

Houve também a "Comissão de Sistematização", responsável por receber, sistematizar e dar parecer às emendas e ao projeto de Constituição construído e enviado a ela por cada comissão temática. A dinâmica dos trabalhos da ANC pode ser resumida da seguinte forma:

Preferiram os Constituintes organizar-se inicialmente em Subcomissões, que preparariam Anteprojetos básicos. Estes serão emendados e votados no âmbito das próprias Subcomissões, em uma primeira etapa; consolidados e novamente votados em comissões temáticas, na segunda; finalmente, reunidos em um texto completo na Comissão de Sistematização. Só então esse texto será apreciado, emendado se for o caso e votado pelo Plenário da Assembléia Nacional Constituinte. (BRASIL, 1988b, p. 2)

Se às classes populares interessava a construção de uma nova carta magna para a nação que rompesse com a ilegalidade vigente no país, instaurasse a democracia e que respeitasse igualmente os interesses de toda a população, às elites políticas e econômicas interessava atá-la à "transição lenta, gradual e segura". Foram esses os interesses que estiveram em disputa durante os trabalhos da ANC, por mais que os discursos dissessem, e ainda digam, o contrário e tentassem apresentá-la "como uma instituição neutra, na qual os 'representantes do povo' estão acima das classes e tratam de elaborar uma Constituição que respeite igualmente os interesses de "todo o povo"" (FERNANDES, 2006, p. 66). Enquanto o Partido do Movimento Democrático Brasileiro (PMDB) e o Partido da

Movimento, Porto Alegre, v. 20, n. 4, p. 1305-1327, out./dez. de 2014. 
Frente Liberal (PFL), que eram partidos de direita - apesar da falta de coesão presente no interior do PMDB que ora se aliava à direita ora à esquerda -, possuíam juntos quase $80 \%$ das cadeiras da ANC, os partidos de esquerda (Partido Democrático Trabalhista - PDT, Partido dos Trabalhadores - PT, Partido Comunista do Brasil PC do B, Partido Socialista Brasileiro - PSB, Partido Comunista Brasileiro - PCB) possuíam apenas 9,8\% das cadeiras ${ }^{7}$ (FREITAS; MOURA; MEDEIROS, 2009; LIMA, 2002), o que evidencia a maior representatividade das elites brasileiras na ANC.

Além dos constituintes outros dois atores políticos participaram do processo constituinte: entidades da sociedade civil e a população. As entidades puderam participar através de três mecanismos: enviando sugestões, enviando emendas, e participando de audiências nas subcomissões temáticas. E a população pôde participar diretamente através do envio de sugestões, em um formulário previamente selado e distribuído pelo Senado Federal em todo o Brasil.

Veremos a seguir a reconstituição sintetizada da trajetória do lazer no processo constituinte de 1987-1988 . Veremos onde o lazer esteve presente e onde ele esteve ausente nos trabalhos da Constituinte. A intenção é revelar em que momentos ele apareceu e através da voz de que atores isso se deu. Ative-me também às ausências do lazer, pois elas são significativas para a compreensão do lugar ocupado por ele e do entendimento de lazer presente na Constituinte.

\section{Entre PRESEnÇAS e AusênCIAS: o LAZER nA Assembleia Nacional Constituinte}

Foram enviadas pela população à "Subcomissão da Família, do Menor e do Idoso" sugestões sobre o direito das "crianças carentes"

\footnotetext{
${ }^{7} \mathrm{~A}$ definição do posicionamento ideológico dos partidos foi realizada a partir do trabalho de Freitas, Moura e Medeiros (2009, p. 10): foram considerados como de "esquerda", o grupo político que teve sua origem no partido de oposição ao regime militar, o Movimento Democrático Brasileiro (MDB); e foram considerados como de "direita" o bloco, em processo de dispersão, que durante o processo de redemocratização estava mais alinhado às forças autoritárias."
}

${ }^{8} \mathrm{O}$ trabalho na integra encontra-se em: SANTOS, 2014.

Movimento, Porto Alegre, v. 20, n. 4, p. 1305-1327, out./dez. de 2014. 
ao lazer. As entidades que se manifestaram nessa subcomissão reivindicaram o lazer como direito do menor abandonado (BRASIL, 1988c, p. 6). Já os constituintes sugeriram que o lazer fosse considerado um direito da criança, e não apenas da criança abandonada ou do menor carente. Mas essas reivindicações não foram incluídas no anteprojeto do relator da subcomissão e voltaram a aparecer nas emendas a esse anteprojeto, mas também não foram acolhidas. No anteprojeto da comissão, a qual pertence essa subcomissão, essa demanda foi atendida, e o lazer foi incluído como um dos direitos do menor.

Entidades reivindicaram o lazer como direito do idoso. E os constituintes, quando se referiram aos idosos, sugeriram que o Estado "deve destinar recursos a fim de assegurar-lhes condições dignas de vida - saúde, habitação, lazer, oferta de trabalho" (BRASIL, 1988c, p. 8). Deste modo, o lazer foi aqui considerado uma das condições de vida digna do idoso. Tais reivindicações também não foram atendidas no anteprojeto do relator, e reapareceram em três emendas dos constituintes que também não foram acolhidas. $\mathrm{O}$ direito do idoso ao lazer também não está presente no anteprojeto da "Comissão da Família, da Educação, Cultura e Esportes, da Ciência e Tecnologia e da Comunicação".

O lazer aparece uma única vez no anteprojeto do relator da "Subcomissão da Família, do Menor e do Idoso", e permaneceu sendo o mesmo no anteprojeto da subcomissão: "Os programas de planejamento familiar levarão em conta as condições de habitação, saúde, educação, cultura e lazer a serem conferidos às famílias." (BRASIL, 1988c, p. 13). Os atores políticos responsáveis por essa presença do lazer foram os constituintes. Partiu unicamente deles a reivindicação pela presença do lazer entre os "deveres do Estado para com a família" (BRASIL, 1988c, p. 7).

A cultura foi tematizada por duas subcomissões: "Subcomissão da Ciência e Tecnologia e da Comunicação" e "Subcomissão da Educação, Cultura e Esportes". População, constituintes e instituições se manifestaram sobre a cultura através de sugestões, emendas e audiências públicas.

Movimento, Porto Alegre, v. 20, n. 4, p. 1305-1327, out./dez. de 2014. 
A cultura foi entendida pelas instituições como direito, e o dever do Estado em concretizá-lo foi enfatizado. Foi comum, nessas sugestões, relacionar cultura à educação. Nenhuma relação foi feita por essas entidades entre cultura e lazer. Mais uma ausência do lazer é representativa. O Sindicato dos Empregados em Entidades Culturais, Recreativas, de Assistência Social, de Orientação e Formação Profissional de Brasília (SENALBA) se manifestou em relação à cultura, mas nada disse em relação ao lazer (BRASIL, 1988d, p. 19). Devido às relações históricas entre o lazer e a recreação no Brasil, podia-se esperar que tal sindicato se manifestasse em relação ao lazer, mas isso não ocorreu. E nenhuma das instituições que possuem a cultura como objeto de sua atuação ou que representam os profissionais que com ela trabalham no Brasil incluíram o lazer entre suas preocupações. O que pode ser sentido ainda hoje, pois o setor da cultura, muitas vezes, não reconhece suas ações como sendo possibilidades de lazer, demonstrando desconhecimento das relações entre lazer e cultura (MUNHOZ, 2006). Essa situação é representativa do lugar ocupado pelo lazer e do desenvolvimento alcançado por ele no atual momento histórico em nosso país.

Os constituintes realizaram relação entre o lazer e a cultura. Roberto Freire (PCB/PE), ao propor a criação de uma "política cultural brasileira" (BRASIL, 1988e, p. 295), considerou como um de seus imperativos "estender as oportunidades da cultura e lazer, unindo recreio e educação" (BRASIL, 1988e, p. 295). Florestan Fernandes (PT/SP) enviou uma longa sugestão, com dez artigos, que tem como tema único o lazer. Ele nos fala de conteúdos culturais do lazer, evidenciando as relações intrínsecas do lazer com a cultura.

- Art. - O Estado protegerá e fomentará as formas popularescas e folclóricas de diversão e de lazer, de acordo com a lei, buscando mantê-las vivas nos núcleos em que são valorizadas socialmente e de disseminá-las em todo o país. A dança, a música, o circo, o teatro, as artes plásticas e o artesanato popularescos ou folclóricos serão objeto de programas de proteção, de exibição e de participação popular.

Movimento, Porto Alegre, v. 20, n. 4, p. 1305-1327, out./dez. de 2014. 
- Art. - O rádio e a televisão serão utilizados, na forma da lei, na valorização, difusão e perpetuação das manifestações popularescas e folclóricas de lazer, indicadas no artigo anterior.

- Art. - O Estado procurará incentivar a difusão de jogos cênicos, do ballet [sic], da música, das artes plásticas e do teatro eruditos, do cinema e da cultura como formas de lazer, especialmente entre os jovens e no seio das populações de baixa renda, de acordo com a lei. (BRASIL, 1988d, p. 44)

A população também se manifestou em torno da cultura e realizou associações entre ela e o lazer. Considerou o lazer como um tema da cultura. O lazer aparece ao lado do esporte e da recreação como o terceiro tema da cultura mais citado nas sugestões populares, o que é muito significativo, pois demonstra que a população compreendia que lazer é cultura, diferentemente do próprio Estado que separa o setor da cultura do setor do lazer, e que ao implementar políticas que tem como objeto a cultura não entende que está implementando possibilidades de lazer. Desconsidera, assim, as relações imbricadas entre lazer e cultura.

O lazer também aparece atrelado ao esporte e ao turismo nas sugestões enviadas pela população, pelas instituições e pelos constituintes. O esporte e o turismo aparecem como formas de lazer. A "Subcomissão da Educação, Cultura e Esportes" ouviu doze entidades especializadas em esporte (BRASIL, 1988d, p. 22). Em torno da cultura vinte instituições se manifestaram nessa subcomissão (BRASIL, 1988d, p. 17-19). Já em torno do lazer, especificamente, nenhuma instituição se manifestou. Ele sempre esteve nas sugestões por elas encaminhadas, entre outras reivindicações.

Relações entre o lazer e a educação foram construídas em emendas. Uma delas sugere que no conteúdo mínimo obrigatório do ensino básico esteja prevista a importância do lazer (BRASIL, 1988d, p. 274). Essa emenda foi acolhida pela subcomissão, com modificação apenas do nível de ensino, mas não foi incluída no anteprojeto da comissão.

Movimento, Porto Alegre, v. 20, n. 4, p. 1305-1327, out./dez. de 2014. 
$\mathrm{Na}$ "Subcomissão dos Direitos dos Trabalhadores e Servidores Públicos", constituintes reivindicaram que a determinação do valor do salário mínimo levasse em consideração o lazer. Reivindicaram também a presença do lazer no título "Da ordem social" (BRASIL, 1988f, p. 287). E o deputado Nelton Friedrich (PMDB/PR), exmembro do $\mathrm{MDB}$, defensor das liberdades democráticas na Constituinte, e defensor dos direitos dos trabalhadores, indicou a inclusão do lazer como direito do trabalhador.

$\mathrm{Na}$ "Subcomissão de Saúde, Seguridade e Meio Ambiente", deputados indicaram a inclusão do lazer como uma das necessidades mínimas das quais resulta a saúde. Essas reivindicações não foram acolhidas pela subcomissão e voltaram a aparecer nos trabalhos da comissão, no entanto mais uma vez não foram acolhidas. Assim, o lazer foi entendido como fator importante para a conquista da saúde, no entanto, sua presença não foi forte o suficiente para conseguir ser incluída nos anteprojetos da subcomissão e da comissão.

No anteprojeto do relator da "Subcomissão dos Direitos Políticos, dos Direitos Coletivos e Garantias", o lazer está presente uma vez: "Art. 23 - É direito de todos o acesso ao trabalho, mediante política de pleno emprego, com remuneração que possibilite moradia, alimentação, saúde, acesso a bens de consumo, educação, cultura e lazer." (BRASIL, 1988f, p. 11). No entanto, o autor desse artigo não foi identificado. Foi dessa forma que o lazer permaneceu no anteprojeto da subcomissão.

O lazer foi reivindicado pelo deputado Ismael Wanderley (PMDB/RN) em uma emenda como uma "necessidade fundamental", um "direito incontestável” na "Subcomissão dos Direitos e Garantias Individuais". Ele considerou ainda, o lazer como "atividade possibilitadora de novas aprendizagens", e entendeu como sendo possibilidades de lazer o teatro, o cinema, a música e a literatura, conteúdos culturais presentes em outros momentos da Constituinte sem que qualquer relação com o lazer fosse construída. No entanto, essa emenda não foi acolhida pela subcomissão e o lazer está lá presente apenas da seguinte forma:

Movimento, Porto Alegre, v. 20, n. 4, p. 1305-1327, out./dez. de 2014. 
Art. [...] São direitos e garantias individuais:

$[\ldots]$

XIX - a utilização criadora do tempo disponível no trabalho ou no lazer; (BRASIL, 1988f, p. 7 e 10)

Ao acolher em seu substitutivo o anteprojeto da "Subcomissão dos Direitos e Garantias Individuais", o relator da "Comissão da Soberania e dos Direitos e Garantias do Homem e da Mulher", senador José Bisol (PMDB/RS) conferiu ao lazer o status de direito, atribuindo, assim, maior importância a ele. Mas a deputada Sandra Cavalcanti (PFL/RJ) sugeriu que o lazer voltasse a ter a configuração que possuía no anteprojeto do relator, deixando assim de ser considerado um direito (BRASIL, 1988g, pp. 82-83), mas sua emenda não foi acolhida. Percebemos, assim, que o entendimento de que o lazer devia ser um direito garantido pela Constituição não foi consenso.

A "Comissão de Sistematização" recebeu os anteprojetos de todas as comissões temáticas e os reuniu, adequando um ao outro para que não houvesse contradições e irregularidades. No primeiro anteprojeto de Constituição produzido por ela as presenças do lazer se mantiveram as mesmas das comissões temáticas, sem qualquer alteração.

As emendas a esse anteprojeto da "Comissão de Sistematização" reivindicaram que o lazer fosse considerado quando da "utilização do solo urbano" (BRASIL, 1988h, p. 201), e que fosse incluído no artigo que trata do "mínimo necessário ao pleno exercício do direito à existência digna e garanti-los é dever do Estado" (BRASIL, 1988h, p. 416), pois segundo seu autor, o deputado Agripino de Oliveira Lima (PFL/SP), "O lazer constitui-se num bem inalienável da condição humana, como reparador do esforço e das energias despendidas nas lidas diárias. É condicionante de melhor finalidade de vida das pessoas, sendo, por assim dizer, o antitrabalho." Assim, o deputado, que havia sido vereador pela ARENA em Presidente Prudente/SP por dois mandatos, entende que o lazer possui uma função específica, a

Movimento, Porto Alegre, v. 20, n. 4, p. 1305-1327, out./dez. de 2014. 
de restabelecer as forças para o trabalho. Evidencia-se aqui uma compreensão funcionalista de lazer, que o vê como importante e necessário por ser útil ao trabalho.

O lazer foi reivindicado ainda nas emendas, como direito de todos (BRASIL, 1988i, pp. 368-369) e como uma das "condições de vida urbana digna" a que todo "cidadão tem direito para si e sua família” (BRASIL, 1988i, pp. 502). Nenhuma dessas emendas foi incorporada ao anteprojeto de Constituição. Na fase seguinte, não apenas os constituintes, mas também a população pode emendar o anteprojeto. Foram enviadas 122 emendas pelas entidades representativas da sociedade, das quais nove trataram do lazer, e as relações nelas construídas foram as mesmas já construídas nas etapas anteriores da Constituinte. O lazer foi relacionado à "justiça social", à "saúde" e ao "salário mínimo". Foi entendido como direito da criança, do adolescente e do idoso. As entidades que enviaram essas emendas eram setores da Igreja Católica, instituições representativas de categorias profissionais diversas, Movimento dos Trabalhadores Sem Terra (MST), Central Única dos Trabalhadores (CUT), entidade científica, movimentos sociais diversos, o que nos revela não uma organização social, mobilização em torno do lazer, já que ele figurava entre outros temas, não sendo central em nenhuma das emendas, mas nos revela também que ele estava entre as preocupações de uma parcela da sociedade brasileira naquele momento, que foi tido como um dos fatores garantidores de condições de vida digna e da justiça social, e foi tido como direito fundamental. Essas noções estão ligadas à natureza dos direitos sociais, que são direitos mínimos e universais, se referem a bens e serviços essenciais aos cidadãos, eles permitem às sociedades reduzir os excessos de desigualdades produzidos pelo capitalismo e garantir um mínimo de bem-estar a todos, estão baseados na ideia da justiça social (MARSHALL, 1967, CARVALHO, 2007).

A partir dessas emendas o relator construiu o seu primeiro substitutivo, no qual o lazer esteve presente uma única vez, como um dos direitos do menor. Todas as demais presenças do lazer que constavam no projeto de Constituição anterior foram suprimidas

Movimento, Porto Alegre, v. 20, n. 4, p. 1305-1327, out./dez. de 2014. 
e as reivindicações em torno do lazer apresentadas nas emendas populares e dos constituintes não foram acolhidas. As emendas a esse substitutivo tentaram reincluir o lazer onde ele havia sido excluído, e surgiu uma reivindicação inédita nesse momento: a criação de políticas de lazer no meio rural. A partir dessas emendas o relator construiu o seu segundo substitutivo que seria enviado ao Plenário. Nele o lazer está presente uma única vez, como direito da criança e do adolescente. Houve apenas uma reivindicação em todo o processo pela inclusão do direito dos adolescentes ao lazer, enviada pelo deputado Florestan Fernandes. Assim, nenhuma das emendas que foram enviadas nessa etapa dos trabalhos versando sobre o lazer foi acolhida pela "Comissão de Sistematização". As presenças do lazer existentes nos anteprojetos das subcomissões e comissões temáticas foram suprimidas, ficando apenas uma, que teve origem na "Comissão da Família, da Educação, Cultura e Esportes, da Ciência e Tecnologia e da Comunicação".

Nas fases que se desenvolveram no Plenário aconteceu o mesmo movimento de tentativa de reinclusão do lazer onde ele havia sido excluído. Os constituintes voltaram a enviar emendas pedindo a inclusão do lazer como uma das "condições de vida urbana digna" a que "todos têm direito"; como uma das "necessidades básicas" que o salário mínimo deve ser capaz de satisfazer; como "forma de promoção social". E pela primeira vez nos trabalhos da ANC uma emenda pediu a inclusão do lazer como direito social.

Art. $7^{\circ}$ - São direitos sociais a educação, a saúde, o trabalho, o lazer, a segurança, a previdência social, o amparo à maternidade e à infância, a assistência as desamparados na forma dessa Constituição. (BRASIL, 1988i, p. 425)

Essa emenda foi assinada por 291 constituintes, dos mais diferentes partidos políticos. Dentre eles Max Rosenmann, Iberê Ferreira, Ismael Wanderley, Stélio Dias que já haviam reivindicado o lazer em outras etapas da Constituinte, mas Florestan Fernandes e José Maurício Linhares Barreto, os dois constituintes que mais reivindicaram o lazer na Constituinte, não assinaram essa emenda. Ela possui 18 artigos, se refere a todo o "Título II - Dos direitos e garantias fundamentais",

Movimento, Porto Alegre, v. 20, n. 4, p. 1305-1327, out./dez. de 2014. 
tratando, assim, de vários assuntos e não apenas do lazer, o que explica o grande número de interessados. Mas uma fonte oral, o deputado José Linhares Barreto (PDT/RJ), nos apresenta outra explicação:

Você sabe o que também pode ter acontecido? [...] o autor da emenda ou um interessado na emenda contratava um funcionário para ficar nos corredores e apanhava assinatura da gente. A gente para não ser indelicado subscrevia a emenda, não sabia nem o que estava assinando, entendeu? Assinava mais por solidariedade. Isso são as chamadas emendas de corredor. É sim, você passava e aí ele dizia: deputado isso aqui é para o deputado fulano de tal e pedia pra pessoa assinar, dar apoio, aí você dá o apoiamento, entendeu?

A partir dessas emendas foi construído o projeto de Constituição (BRASIL, 1988j) que foi encaminhado ao segundo turno de discussão e votação no Plenário da Constituinte. Nele as presenças do lazer sofreram grandes modificações quando comparadas às presenças existentes até então nos anteprojetos produzidos. A emenda que incluiu o lazer entre os direitos sociais foi acolhida sem qualquer modificação ${ }^{9}$, e o lazer adquiriu, assim, pela primeira vez em um projeto de Constituição, o status de direito social. As indicações de que o lazer devia ser considerado para o cálculo do valor do salário mínimo também foram incorporadas ao projeto. A emenda que reivindicou o lazer "como forma de promoção social" também foi incluída, passando a figurar na "Seção III - Do Desporto", indicando relações construídas entre o lazer e o esporte.

\section{Conclusão}

Tendo em vista a natureza dos direitos sociais, não houve mobilização e organização em torno do lazer que justificasse sua definição como direito social na Constituição. Essa reivindicação

${ }^{9}$ Apenas o número do artigo mudou, na emenda o artigo é o $7^{\circ}$ e no projeto de Constituição (B) o artigo é o $6^{\circ}$.

Movimento, Porto Alegre, v. 20, n. 4, p. 1305-1327, out./dez. de 2014. 
explícita não foi feita por nenhum ator político. Nem mesmo os trabalhadores, a quem recorrentemente na história essa responsabilidade é imputada, realizaram essa reivindicação. Foi no último momento dos trabalhos da Constituinte, no Plenário, quando os únicos atores políticos participantes do processo eram os constituintes, que o lazer apareceu pela primeira vez em uma emenda como direito social. Essa emenda tratou de vários temas referentes aos direitos e garantias individuais, apresentou uma proposta de redação para todo o título da constituição que trataria desses temas. Não há qualquer outro registro de reivindicação da definição do lazer como direito social nessa etapa dos trabalhos, ou em qualquer outra. $\mathrm{O}$ que nos permite concluir que a inclusão do lazer no artigo que define os direitos sociais foi obra dos constituintes, foram eles os responsáveis por isso, pela definição do lazer como direito social na Constituição de 1988.

Não é que não tenha havido reivindicações por lazer nos trabalhos da ANC, como demonstrado nesse trabalho elas existiram. Mas o meu argumento é que pelo fato de elas não terem partido de parcela significativa da população ${ }^{10}$, e de não ter havido organização popular e movimentos sociais organizados ou lobbys em torno desse tema, tais reivindicações não foram suficientes para conferir o status de direito social ao lazer, e tampouco para incluí-lo na Constituição como tal. Assim, apesar de ter havido reivindicações por lazer na $\mathrm{ANC}$, elas não foram suficientes para justificar a definição do lazer como direito social na Constituição brasileira.

A nenhum interesse de setores comerciais pode ser imputada essa inclusão, pois eles não estiveram presentes no processo constituinte em torno do lazer. Interesses ideológico-partidários em torno do lazer também não estiveram presentes. O que parece é que compreensões individuais de lazer, do lugar que ele deveria ocupar prevaleceram e foram responsáveis por sua definição como direito social.

${ }^{10}$ Quantitativamente falando.

Movimento, Porto Alegre, v. 20, n. 4, p. 1305-1327, out./dez. de 2014. 
Os significados de lazer não foram homogêneos. Foi possível percebê-los através das relações construídas entre ele e a saúde, o esporte, o turismo, as atividades culturais, a cultura. $\mathrm{O}$ lazer foi entendido como simples "atividade" por alguns, como "direito fundamental" por muitos, como importante à "realização integral do ser humano" e "possibilitador de novas aprendizagens" por outros, e como uma das "necessidades básicas" dos cidadãos por muitos outros. Revelando a presença de compressões simplistas de lazer, que o reduzem a mera atividade, ao lado de compreensões mais complexas que o relacionam à educação e à cultura, e o tem como necessidade dos cidadãos.

Looking for leisure in the constitution: its inclusion as a right in Brazil's 1988 constitution

Abstract: This paper summarizes the history of leisure in Brazil's National Constituent Assembly of 1987-1988, identifying the political actors responsible for its inclusion as social right in the Constitution as well as the interests and the meanings of leisure involved in the process. Its sources are the documents produced by the National Constituent Assembly. The indications we found allow us to perceive that although leisure was considered central to the lives of Brazilian citizens by all political actors participating in that process, there was no mobilization and organization around leisure to justify its definition as a social right in the Constitution.

Keywords: History. Leisure. Social right.

\section{Historia de la inclusión del ocio como derecho social en la constitución brasileña de 1988 \\ Resumen: Este artículo reconstruye la trayectoria del ocio en la Asamblea Nacional Constituyente de 1987-1988, identificando a los actores políticos responsables por su inclusión como un derecho social en la Constitución, así como los intereses y significados del ocio involucrados en este proceso. Las fuentes fueron los documentos elaborados por la Asamblea Nacional Constituyente de 1987-1988. Los rastros nos permiten percibir que aunque el ocio ha sido entendido como un elemento central en la vida de los ciudadanos brasileños por todos los actores políticos de este proceso, no hubo movilización y organización en torno al ocio para justificar su definición como un derecho social en la Constitución. \\ Palabras clave: Historia. Ocio. Derecho social.}




\section{REFERÊNCIAS}

ARRETCHE, Marta T. S. Emergência e desenvolvimento do Welfare State: teorias explicativas. Boletim Informativo e Bibliográfico de Ciências Sociais, Rio de Janeiro, n.39, p. 3-40, $1^{\circ}$ semestre de 1995.

BRASIL. Constituição da República Federativa do Brasil: Texto constitucional promulgado em 05 de outubro de 1988, com alterações adotadas pelas Emendas Constitucionais de Revisão nํㅗ 1/92 a 56/2007 e pelas Emendas Constitucionais de revisão nos 1 a 6/94. Brasília: Senado Federal, Subsecretaria de Edições Técnicas, 2008.

BRASIL. Assembleia Nacional Constituinte (1987-1988). Comissão da Família, da Educação, Cultura e Esportes, da Ciência e Tecnologia e da Comunicação. Subcomissão da Ciência e Tecnologia e da Comunicação. Relatório e anteprojeto. 1988a. Relatora Cristina Tavares. <http://www.camara.gov.br/internet/ constituicao20anos/DocumentosAvulsos/vol-210.pdf>.

BRASIL. Anteprojeto do Relator João Calmon da "Subcomissão da Educação, Cultura e Esportes",1988b. <http://www.camara.gov.br/internet/ constituicao20anos/DocumentosAvulsos/vol-207.pdf>.

BRASIL. Anteprojeto do Relator Eraldo Tinoco da "Subcomissão da Família, do Menor e do Idoso", 1988c. <http://www.camara.gov.br/internet/ constituicao20anos/DocumentosAvulsos/vol-214.pdf $>$.

BRASIL. Anteprojeto do Relator João Calmon da "Subcomissão da Educação, Cultura e Esportes", 1988d. <http://www.camara.gov.br/internet/ constituicao20anos/DocumentosAvulsos/vol-207.pdf>.

BRASIL. Emendas ao anteprojeto do relator da "Subcomissão da Educação, Cultura e Esportes", 1988e. <http://www.camara.gov.br/internet/ constituicao20anos/DocumentosAvulsos/vol-208.pdf>.

BRASIL. Emendas ao Anteprojeto do Relator da "Subcomissão dos Direitos dos Trabalhadores e Servidores Públicos", emenda do deputado Stélio Dias, $1988 f$. $<$ http://www.camara.gov.br/internet/constituicao20anos/DocumentosAvulsos/vol189.pdf>.

BRASIL. Emendas ao Substitutivo do Relator da "Comissão da Soberania e dos Direitos e Garantias do Homem e da Mulher", emenda da deputada Sandra Cavalcanti, 1988g. <http://www.camara.gov.br/internet/constituicao20anos/ DocumentosAvulsos/vol-67.pdf>.

BRASIL. Emendas oferecidas ao Anteprojeto de Constituição, v. 1, 1988h. $<$ http://www.camara.gov.br/internet/constituicao20anos/DocumentosAvulsos/vol221.pdf $>$.

BRASIL. Emendas oferecidas ao Anteprojeto de Constituição, v. II, emenda do deputado Theodoro Mendes, 1988i. <http://www.camara.gov.br/internet/ constituicao20anos/DocumentosAvulsos/vol-222.pdf>.

Movimento, Porto Alegre, v. 20, n. 4, p. 1305-1327, out./dez. de 2014. 
BRASIL. Projeto de Constituição (B) - Redação para o segundo turno de discussão e votação, 1988j. <http://www.camara.gov.br/internet/constituicao20anos/ DocumentosAvulsos/vol-299-sup01.pdf>.

BRASIL. Resolução $\mathbf{n}^{\circ} \mathbf{2}$, de 25 de março de 1987 . <http://apache. camara.gov.br/portal/arquivos/Camara/internet/constituicao20anos/ publicacoes/regimento-interno-da-assembleia-nacional/Regimento\%20ANC Resolu\%C3\%A7\%C3\%A30\%202-1987.pdf>.

BRASIL. Emenda Constitucional n 26, de 28 de novembro de 1985. <http://apache. camara.gov.br/portal/arquivos/Camara/internet/constituicao20anos/assembleianacionalconstituinte/linhadorabtempo/Emenda\%20Constitucional\%2026\%201985\%20 p\%C3\%A1g\%201\%20e\%202.pdf>.

BRUNHS, H. Lazer e ciências sociais: diálogos pertinentes. São Paulo: Chronos, 2002.

CARVALHO, J. M. Cidadania no Brasil: o longo caminho. 9. ed. Rio de Janeiro: Civilização Brasileira, 2007.

COIMBRA, Marcos Antônio. Abordagens teóricas ao estudo das políticas sociais. In: ABRANCHES, S. H. et al. Política social e combate à pobreza. Rio de Janeiro: Jorge Zahar, 1987.

FARIA, Carlos Aurélio Pimenta de. Uma genealogia das teorias e modelos do Estado de Bem-Estar Social. In: DELGADO, M. G; PORTO, L. V. O estudo do bem-estar social no século XXI. São Paulo: LTR, 2007.

FERNANDES, F. Pensamento e ação: o PT e os rumos do socialismo. 2. ed. São Paulo: Globo, 2006.

FREITAS, R; MOURA, S; MEDEIROS, D. Procurando o Centrão: direita e esquerda na Assembléia Nacional Constituinte 1987-88. Concurso ANPOCS - Fundação FORD: Melhores trabalhos sobre a Constituição de 1988, 2009. Disponível em: <http://www. centrodametropole.org.br/v1/constituinte freitas moura medeiros.pdfl>. Acesso em: 03 novembro 2009.

GASPARI, Elio. A ditadura derrotada. São Paulo: Companhia da Letras, 2003.

LIMA, Luziano. A atuação da esquerda no processo constituinte: (1986-1988). 2002. 541 f. Dissertação (Mestrado em Ciência Política) - Instituto de Filosofia e Ciências Humanas, Universidade Estadual de Campinas, Campinas, 2002.

LINHALES, Meily Assbú. São as políticas públicas para a educação física/ esportes e lazer, efetivamente políticas sociais? Motrivivência, Florianópolis, v. 10, n. 11, p. 71-81, jul. 1998.

MAGNANI, José Guilherme. Quando o campo é a cidade: fazendo antropologia na metrópole. In: MAGNANI, José Guilherme; TORRES, Lillian L. (Org.). Na metrópole: textos de antropologia urbana. São Paulo: EDUSP/FAPESP, 1996.

MARCELLINO, N. O lazer e os espaços na cidade. In: ISAYAMA, H.; LINHALES, M. (Orgs.). Sobre lazer e política: maneiras de ver, maneiras de fazer. Belo Horizonte:

Movimento, Porto Alegre, v. 20, n. 4, p. 1305-1327, out./dez. de 2014. 
Procurando o lazer na constituinte: sua inclusão como ...

Editora UFMG, 2006.

MARSHALL, T. H. Cidadania, classe social e status. Rio de Janeiro: Zahar, 1967.

MELO, V. A; ALVES JUNIOR, E. D. Introdução ao lazer. Barueri: Manole, 2003.

MENICUCCI, Telma. Políticas públicas de lazer: questões analíticas e desafios políticos. In: ISAYAMA, H. F; LINHALES, M. A. (Org.). Sobre lazer e política: maneiras de ver, maneiras de fazer. Belo Horizonte: Editora UFMG, 2006.

MUNHOZ, Virna. O lazer como direito social na prefeitura de Belo Horizonte. 2006. 115 f. Dissertação (Mestrado em Administração Pública) - Escola de Governo Prof. Paulo Neves de Carvalho da Fundação João Pinheiro, Belo Horizonte, 2006.

REQUIXA, Renato. O lazer no Brasil. São Paulo: Brasiliense, 1977.

SALGADO, E. D. Tijolo por tijolo em um desenho (quase) lógico: vinte anos de construção do projeto democrático brasileiro. 2005. 244 f. Dissertação (Mestrado em Direito do Estado) - Programa de Pós-Graduação em Direito, Setor de Ciências Jurídicas, Universidade Federal do Paraná, Curitiba, 2005.

SANTOS, Flávia da Cruz. O Lazer como direito social: sua inclusão na Constituição de 1988. São Paulo: Annablume/Fapesp, 2014.

STIGGER, Marco Paulo. Políticas sociais em lazer, esportes e participação: uma questão de acesso e de poder ou subsídios para tomar uma posição frente à pergunta.... Motrivivência, Santa Catarina, v. 10, n. 11, p.83-96, set. 1988.

VERONEZ, Luiz Fernando Camargo. Quando o Estado joga a favor do Privado: as políticas de Esporte após a Constituição de 1988. 2005. 386 f. Tese (Doutorado em Educação Física) - Faculdade de Educação Física, Unicamp, Campinas, 2005.

VERSIANI,MariaHelena.Cartascidadãs. In:ENCONTRODEHISTÓRIAANPUH-RIO, XIII,2008,Riode Janeiro.Anais eletrônicos...Riode Janeiro:ANPUH,2008. Disponível em: $\quad<$ http://encontro2008.rj.anpuh.org/resources/content/anais/1213210085 ARQUIVO 2008ANPUHregionalTextofinalSeropedicareduzido.pdf >. Acesso em: 07 novembro 2010.

VIEIRA, Liszt. Cidadania global e Estado nacional. Dados, Rio de Janeiro, v. 42 , n. 3, p. 1-17, 1999.

Endereço para correspondência:

R. Beira Alta, 515, São Francisco,

Belo Horizonte, MG.

Cep 31255-240

Recebido em: 21.11.2013

Aprovado em: 14.05.2014

Movimento, Porto Alegre, v. 20, n. 4, p. 1305-1327, out./dez. de 2014. 